\title{
BENEFÍCIOS INDIRETOS DA FLORESTA
}

\author{
Joelmir Marques da Silva ${ }^{1}$ \\ ${ }^{1}$ Biólogo, Mestrando do Programa de Pós-Graduação em Ciências Florestais, Departamento de Ciência Florestal, Rua Dom Manoel de Medeiros, s/n, \\ Universidade Federal Rural de Pernambuco (UFRPE). Dois Irmãos. CEP: 52171-900. Pernambuco, Brasil. \\ E-mail: joelmir_marques@hotmail.com
}

\section{RESUMO}

No presente trabalho, foram apresentados os métodos para avaliar os benefícios indiretos da floresta. Após exposições sobre a definição, as diferenças entre os conceitos e as características dos benefícios indiretos, foram descritos os problemas fundamentais da avaliação e as vantagens e desvantagens dos diferentes métodos. A última parte do estudo trata dos incentivos atuais e problemas a contexto, adotados na Alemanha, na produção florestal. Palavras-chave: Benefícios indiretos, avaliação, incentivos, Alemanha.

\section{ABSTRACT}

SOCIAL BENEFITS OF THE FOREST. In the present work the methods for evaluating the social benefits of the forest are introduced. After discussions about the definition, the differences between the nations and the characteristics of the social benefits, the fundamental problems of evaluation and the advantages and disadvantages of the diferent methods are described. The last part deals with the present subsidies and context problems, adopted in Germany, in forest production.

Keywords: Social benefits, valuation, subsidies, Germany.

\section{DEFINIÇÃO}

Ao lado da produção de madeira (produção de bens materiais), a floresta e a produção florestal produzem bens imateriais que são conceituados como benefícios indiretos (social benefits), tarefas secundárias, ou produções de infra-estrutura, ou seja, todas as disposições e normas necessárias para a existência e o desenvolvimento da economia e da sociedade (Kapp 1979). Segundo Tromp (1971) esses benefícios indiretos são: manutenção da fertilidade do solo; do regime de água; da limpeza do ar; e da recreação para os habitantes dos centros urbanos, etc.

O conjunto de todos esses benefícios, ou seja, a produção de bens materiais e imateriais chama-se de 'uso-múltiplo' da floresta.

\section{DIFERENÇAS ENTRE CONCEITOS}

No passado, havia na literatura algumas tentativas para diferenciar os vários benefícios indiretos. Tromp (1971) distingue entre benefícios indiretos naturais que partem da floresta e que são importantes para a sociedade e, por outro lado, benefícios indiretos produzidos que representam as produções advindas dos investimentos da produção florestal. Niesslein (1979) faz uma outra distinção: diferenciam entre efeitos externos que são medidos pelo benefício produzido para o público e efeitos internos como resultados positivos na área da propriedade. Outra importante noção, nesta conexão, são as 'funções da floresta'. A idéia predominante é que a floresta reúna três funções: a função de exploração, a de proteção e a de recreação. Segundo essa teoria, que foi criada nos anos 60 na Alemanha, todas as funções da floresta são postas à disposição pela produção florestal. Nesse sentido, Brandl \& Oesten (1966) destacam, num parecer, a distinção entre os efeitos da floresta e as produções da atividade florestal. Essa distinção deve substituir, na opinião dos autores, a prévia idéia das três funções.

Em geral, o número de trabalhos na área dos benefícios indiretos não é muito grande. Além dos estudos já mencionados, existem trabalhos de Spathelf (1988), Schäfer (1989), Oesten (1994) que, especialmente, se ocupam das funções recreativas da floresta na Alemanha. 
CARACTERÍSTICIAS DOS BENEFÍCIOS INDIRETOS

A primeira característica dos benefícios indiretos é a falta de valor e os efeitos e as produções são entregues e consumidas sem um preço de mercado, ou seja, eles são um bem público: nenhuma rivalidade existe entre os usuários (non-rivalry) e nenhuma exclusão é possível (non-excludability). Para Brandl \& Oesten (1996), há três causas para explicar a falta do valor de mercado:

1. é inconveniente e/ou inoportuno quantificar e controlar o valor desse benefício por causa do grande trabalho para sua determinação;

2. é politicamente indesejado;

3. é impossível por causa dos argumentos técnicos e jurídicos.

Uma outra característica dos benefícios indiretos é que são, muitas vezes, o fundamento para a produção de outros bens e estão ligados ao sítio. Em último lugar, o grande número e as diferentes maneiras em que se manifestam provocam conflitos de objetivo ou de meta (ex.: meta de 'proteção da natureza' contra a meta de 'recreação').

\section{BENS PÚBLICOS E PRIVADOS}

Os bens privados são caracterizados pelos direitos exclusivos para usar e dispor, enquanto os bens públi- cos são totalmente o oposto. Na teoria, essa diferença entre bens privados e públicos é fácil de ser determinada, mas na prática existem muitos casos nos quais a separação é difícil como, por exemplo, a floresta (Petri 1971). Por um lado, a floresta é um bem privado como um fornecedor de matérias-primas (madeira) e um local de atividades econômicas (construção das estradas, caça etc.).

Por outro lado, segundo Brandl \& Oesten (1996) a floresta é um bem público como um meio de recepção para elementos e efeitos secundários (poluição do ar, barulho, proteção visual, proteção contra deslizamentos, entre outros), como um bem de consumo, ou seja, por causa do direito das pessoas de entrar na floresta. O fato da floresta ser também um bem público, traz conseqüências negativas. O preço 'zero' significa abundância, por isso existe uma superutilização trazendo danos à floresta.

\section{AAVALIAÇÃO DOS BENEFÍCIOS INDIRETOS}

A determinação do valor de benefícios indiretos da floresta para comunidade e para o proprietário é somente uma parte da avaliação florestal, conforme caracterizado na Tabela I.

A avaliação florestal pode ser subdividida na chamada 'teoria do valor da floresta' e na 'prática da avaliação florestal'. A avaliação dos benefícios indiretos encontra-se na área da teoria de valor da floresta.

Tabela I. Posição dos benefícios indiretos na avaliação florestal.

\begin{tabular}{l|l}
\hline \multicolumn{2}{c}{ AAVALIAÇÃO FLORESTAL } \\
\hline Teoria do valor da floresta & Prática da avaliação florestal \\
1. Tarefas e normas da avaliação florestal & $\begin{array}{l}\text { 1. Valor de venda (terreno e povoamento) } \\
\text { 2. Avaliação florestal clássica }\end{array}$ \\
2.1. Avaliação do terreno & $\begin{array}{l}\text { 2ela separação dos povoamentos, por exemplo, pela cons- } \\
\text { truão das estradas, danos pelas emissões) }\end{array}$ \\
2.2. Avaliação do povoamento & 3. Avaliação para tributação \\
- Valor dos rendimentos esperados & \\
- Valor de custo & \\
- Valor de mercado & \\
2.3. Avaliação de classe de manejo & \\
2.4. Taxa de juros na avaliação florestal & \\
3. Valor dos benefícios indiretos da floresta & \\
\hline
\end{tabular}

FONTE: Brandl \& Oesten (1996). 
Os motivos para sua determinação podem ser distintos na empresa florestal e na economia pública.

$\mathrm{Na}$ empresa florestal, refere-se, sobretudo, ao problema da rentabilidade que deve ser considerada em conexão com os benefícios indiretos. Para pôr os benefícios indiretos à disposição da população surgem mais gastos e menos renda na empresa florestal (Petri 1971). Esses gastos dependem da distância dos centros urbanos, pois quanto mais próximo estiver a floresta do centro urbano maior será o valor despendido na construção das estradas para circulação, para relações públicas (material informativo, informações para os visitantes) e pelas maiores dificuldades na empresa florestal (por exemplo renúncia ao trabalho com máquinas grandes). A menor renda surge pela renúncia à transformação dos povoamentos com uma produtividade baixa, mas com uma grande atratividade para os visitantes, e pelos danos causados pelos visitantes ao solo e aos povoamentos.

Ao avaliar-se o valor dos benefícios indiretos, apresentam-se alguns problemas. O mais importante é que a contabilidade da empresa, na maioria dos casos, não está preparada para tal como, por exemplo, o problema da distribuição de custos de administração, ou para considerar que uma medida aplicada na empresa serve para diferentes objetivos. Um outro problema é que os investimentos realizados, na infraestrutura da floresta, são feitos sem avaliar o interesse do público, examinando-se somente o lado da oferta, isso é, avalia-se a sua existência e não a sua real necessidade (Spathelf 1988).

A respeito da política econômica, trata-se do planejamento e da alocação de recursos. Entre as avaliações, numa empresa florestal e as avaliações de uma política econômica, existem diferenças que são chamadas 'externalidades', ou seja, as produções e os efeitos na cadeia produtiva, não sendo contabilizados pelas empresas florestais.

Kapp (1979) faz uma distinção entre as relações no mercado e as relações no meio ambiente. As relações no mercado são processos de troca e as relações no meio ambiente são relações fora do mercado, entre a produção e o meio ambiente e entre o meio ambiente e a pessoa.

Nessa conexão, pode-se considerar:

1. Custos sociais (efeitos negativos para terceiros ou a sociedade que significam receitas ou vantagens para o produtor, por exemplo, a floresta como solução para a poluição de água e ar);

2. Benefícios sociais (efeitos positivos para ter- ceiros ou para a sociedade, significando despesas ou desvantagens para o produtor, p.ex. os benefícios indiretos da floresta).

\section{PROBLEMAS FUNDAMENTAIS DA AVALIA- ÇÃO DOS BENEFÍCIOS INDIRETOS}

No contexto da avaliação dos benefícios indiretos da floresta há problemas principais. Para avaliar os benefícios indiretos é necessário conhecê-los, ou seja, com palavras simples, o que não se sabe, não se pode conhecer. Por isso, só determinados benefícios indiretos são conhecidos. Um exemplo pode ilustrar isso: só há poucos anos se sabe que as florestas do mundo têm importância no 'efeito estufa', mediante isso foi possível determinar o valor das florestas a esse respeito (Schäfer 1989).

Outro problema é que a descrição dos benefícios indiretos pode ser difícil, porque, às vezes, benefícios indiretos positivos têm também efeitos negativos. Um exemplo são as bordaduras da floresta. Elas são importantes para a proteção contra os ventos dentro dos povoamentos, mas podem causar uma aglomeração do ar frio que produz perdas de produção nas áreas agrícolas (Spathelf 1988).

Ao lado disso, existe o problema que muitas vezes a descrição de um benefício inclui uma avaliação, o que requer critérios claros e bem-definidos. Por outro lado, a quantificação dos benefícios indiretos, ou seja, a avaliação é muito difícil, porque, em princípio, a noção 'avaliação objetiva' é paradoxal, pois os critérios de avaliação são sempre subjetivos na quantificação dos benefícios indiretos.

\section{MÉTODOS DE AVALIAÇÃo}

Na Tabela II, são apresentados os métodos para avaliar o valor dos benefícios indiretos da floresta. Primeiramente, é possível diferenciar entre métodos não-monetários e monetários. Os métodos monetários podem ser subdivididos em métodos de custo e em métodos orientados ao benefício, ou à demanda.

\section{A. MÉTODOS NÃO-MONETÁRIOS A.1. MÉTODOS COM ESCALAS NOMINAIS}

Para Oesten (1994), os métodos com escalas nominais distinguem entre o caso em que o benefício indireto existe, ou não existe, isto é, 'nominal' significa apenas uma classificação dos benefícios indiretos. 
Tabela II. Métodos de avaliação dos benefícios indiretos da floresta.

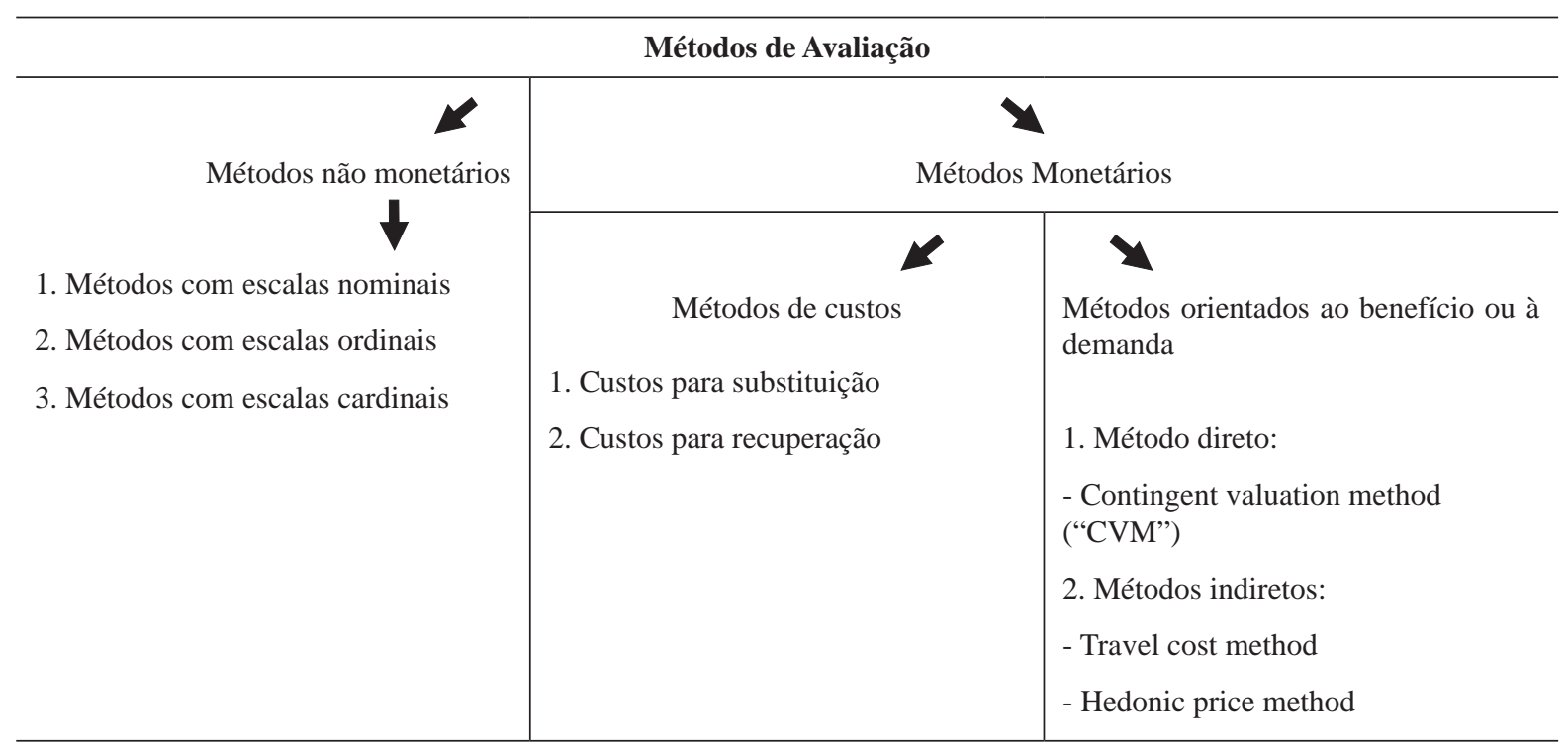

FONTE: Brandl \& Oesten (1996).

Um exemplo é o mapeamento das funções da floresta na Alemanha (recreação, água, proteção do solo, etc.). É importante afirmar que nesse método só a oferta dos benefícios é medida, mas não a demanda.

\section{A.2. MÉTODOS COM ESCALAS ORDINAIS}

Nesse método é possível uma formação hierárquica de benefícios, mas nenhuma consideração pode ser feita sobre suas diferenças de valor. Um exemplo é o mapeamento dos biótopos florestais em BadenWürttemberg na Alemanha, ou seja, a atribuição de cifras aos biótopos florestais (Oesten 1994). Aqui, embora se possa dizer que a cifra 'um' é melhor que a cifra 'dois', não se pode determinar a diferença entre as duas. Nesse contexto também só a oferta natural é considerada, mas não a demanda das pessoas.

\section{A.3. MÉTODOS COM ESCALAS CARDINAIS}

Nos métodos com escalas cardinais, a diferença entre os valores é determinada. Nesse contexto, existem sobretudo três métodos diferentes. Um método é o da análise de valor de benefícios (scoring model). Trata-se de um método para a avaliação de alternativas econômicas, mas tem também critérios que não são medidos como unidades monetárias, ou seja, critérios técnicos, sociais ou psicológicos.

Ao contrário dele, existe a análise de custos e be- nefícios (cost-benefit-analysis). Trata-se de um método de avaliação comparada de projetos ou de alternativas de ações. Esse método, sobretudo, é usado para avaliar projetos públicos de investimento.

Os índices são uma terceira possibilidade no contexto dos métodos de escalas cardinais. Nele, os custos de produção dos benefícios indiretos podem ser expressos em relação aos custos totais na empresa.

\section{B. MÉTODOS MONETÁRIOS \\ B.1. MÉTODOS DE CUSTOS}

A idéia fundamental é que os benefícios indiretos valem, pelo menos, tanto quanto os custos para a sua oferta ou para a substituição. Um exemplo de custo de substituição refere-se aos custos para a preparação da água oriunda de uma área sem floresta em relação à produzida em uma área florestal (Brandl \& Oesten 1996). Os custos de recuperação referem-se aos custos para a reparação de danos que surgem em áreas sem floresta, por exemplo, os danos causados pela erosão do solo.

\section{B.2. MÉTODOS ORIENTADOS AO BENEFÍCIO OU À DEMANDA}

Segundo Petri (1971), Como o benefício das pessoas, que consomem, não é diretamente mensurável, o conceito de 'disposição de pagar' é utilizado, ou 
seja, um bem dá tanto benefício quanto uma pessoa ou a sociedade precisa ou pode pagar. A disposição de pagar por benefícios indiretos existe, porque possibilitam o consumo (user benefits) e trazem outros valores agregados (non user-benefits), tais como:

- o valor de possibilidade - a disposição de pagar existe, porque garante a possibilidade para usar o bem mais tarde;

- o valor de patrimônio - o bem é útil, porque os descendentes poderão usá-lo;

- o valor de existência - o bem tem utilidade pela sua simples existência, embora possa, em um determinado momento, não ser utilizado.

\section{MÉTODO DIRETO: "CONTINGENT VALUA- TION METHOD” (CVM)}

O método trabalha com pesquisa de pessoas sobre suas disposições de pagar por um determinado bem. O método é muito fácil, porque basta entrevistar as pessoas que caminham, que vão de bicicleta ou fazem uma corrida na floresta (Elsasser 1974).

O método, porém, tem uma série de desvantagens. A disposição de pagar é influenciada pela capacidade de pagar, ou seja, quanto maior o salário tanto maior a disposição de pagar. Em virtude a disposição em pagar ser desigual entre as pessoas, é necessário considerar os diferentes níveissalariais. Além disso, é preciso considerar que somente as pessoas, com um salário próprio, podem decidir independentemente.

Uma outra desvantagem é o fato que há respostas estratégicas (respostas não verdadeiras) ou que as respostas verdadeiras não são idênticas ao comportamento das pessoas. E que, ainda pode existir um problema de informação. Os assuntos sobre os quais as pessoas são perguntadas são complexosB, podem representar conflitos entre gerações, entre outros. Uma questão que precisa ser refletida é se temos hoje condições para avaliar bens, que também atingem as próximas gerações? Estamos frente a uma questão ética e moral (Brandl \& Oesten 1996).

\section{MÉTODOS INDIRETOS}

A idéia fundamental nos métodos indiretos é que, com base no comportamento do usuário, será deduzido o valor para os benefícios indiretos.

\section{D.1. MÉTODO DE CUSTO DE VIAGEM: "TRAVEL COST METHOD”}

Segundo Oesten (1994), neste método, o valor do benefício indireto é atribuído em função do custo médio dos visitantes para chegar à floresta. Para isso, é decisivo conhecer o preço pago pela passagem de ônibus, do trem ou do combustível gasto.

Em contraposição ao Contingent valuation method, aqui não se apresenta nenhuma resposta estratégica. O método, porém, apresenta desvantagens, pois só é aplicável à função de recreação, enquanto o Contingent valuation method é também aplicável para outras funções, como por exemplo para averiguar a disposição de pagar pela água limpa originada da floresta.

O Travel cost method trabalha com uma série de suposições, como cada pessoa é observada sozinha, ou seja, considera-se que realizou a viagem sozinha, mesmo que ela tenha sido realizada em grupo - cada membro do grupo é avaliado isoladamente. Uma outra suposição é que a visita à floresta tenha sido o único motivo para a viagem, mesmo que existam outros, como por exemplo uma visita a amigos. Por isso a relação entre a distância de viagem e o benefício de recreação é baixo, pois o método só quantifica o valor da recreação (Brandl \& Oesten 1996).

\section{2. MÉTODO DO VALOR DO TERRENO: "HEDONIC PRICE METHOD”}

Este método, desenvolvido por Petri (1971), é baseado no preço do terreno, ou seja, faz-se a comparação dos preços de mercado dos terrenos junto à floresta com outros mais distantes. Os terrenos devem ser idênticos, deduzindo-se da diferença dos preços, o valor dos benefícios.

\section{INCENTIVOS DAS EMPRESAS FLORESTAIS}

Brandl \& Oesten (1996) fizeram um estudo sobre a avaliação monetária dos impactos causados pela produção florestal (efeitos externos positivos e negativos) na Alemanha. Verificaram que há um grande número de casos nos quais os efeitos positivos refletem na empresa florestal.

Esses efeitos foram disponibilizados para as comunidades na forma de água, ar, redução de ruído, 
recreação, entre outros. Os incentivos recebidos pelas empresas florestais são um exemplo para isso, conforme apresentado na Tabela III.

A mais importante norma da Constituição da Alemanha é a proteção da propriedade privada e, nesse sentido, a garantia das produções da floresta para o bem público é uma atribuição das empresas florestais. A idéia fundamental é que a empresa florestal mantenha uma boa saúde econômica. A garantia das produções dos bens materiais e imateriais, para o bem público, advindo da floresta fica ameaçada, quando a empresa florestal encontra dificuldades econômicas originadas pelas baixas rendas ou pelos efeitos negativos do forte compromisso social.

Por isso, estados como o de Baden-Württemberg e mesmo em toda Alemanha mantêm uma política de incentivo às empresas florestais.

\section{SITUAÇÃO ATUAL DOS INCENTIVOS FLO- RESTAIS NA ALEMANHA}

Brandl \& Oesten (1996) citam que existem alguns problemas atuais com os incentivos florestais na Alemanha.

Tabela III. Incentivos às empresas florestais em Baden-Württemberg no ano 1993.

\begin{tabular}{|c|c|}
\hline & Milhões US\$/ano \\
\hline \multicolumn{2}{|l|}{ A. Incentivos no sentido estrito } \\
\hline \multicolumn{2}{|l|}{ 1. Incentivos diretos } \\
\hline Cooperativas de empresas florestais & 0,28 \\
\hline Florestamento & 1,39 \\
\hline Construção de estradas & 0,67 \\
\hline Tratamentos silviculturais & 0,72 \\
\hline Transformações de povoamentos & 0,28 \\
\hline Replantios & 0,1 \\
\hline Programa especial “Silvicultura” & 2,8 \\
\hline Medidas para a recuperação de novos danos florestais (adubação, reflorestamento, etc.) & 5,5 \\
\hline Recuperação de danos florestais extraordinários causados por catástrofes naturais & 7,8 \\
\hline \multicolumn{2}{|l|}{ 2. Incentivos indiretos } \\
\hline $\begin{array}{l}\text { Apoio à floresta privada (incluído da formação/instrução, aperfeiçoamento e } \\
\text { ajuda técnica) }\end{array}$ & 25,0 \\
\hline Apoio à floresta municipal & 21,7 \\
\hline Reforma agrária na floresta & não-divulgado \\
\hline \multicolumn{2}{|l|}{ B. Subvenções } \\
\hline Prêmio pelo florestamento & 0,1 \\
\hline Subvenções para empresas com 5-20 ha de floresta (só empresas florestais) & \\
\hline ou de 3-200 ha de floresta (empresas com atividade florestal e agrícola) & 9,0 \\
\hline Redução de impostos & não-divulgado \\
\hline $\begin{array}{l}\text { Promoção da produção e de vendas (p.ex.: redução de preço da gasolina } \\
\text { para máquinas grandes) }\end{array}$ & não-divulgado \\
\hline \multicolumn{2}{|l|}{ C. Pagamentos compensado } \\
\hline Programa especial 'Floresta ecológica’ & 0,28 \\
\hline \multicolumn{2}{|l|}{ D. Remunerações pela produção } \\
\hline Incentivos à formação de parques e reservas naturais & 1,1 \\
\hline Total & 76,72 \\
\hline Total/ha/ano ${ }^{1}$ & 80,00 - US\$ \\
\hline
\end{tabular}

FONTE: Brandl \& Oesten 1996.

Obs.: Em razão da impossibilidade em se obter dados de alguns programas de incentivo, a soma dos valores da Tabela III é, com certeza, superior à apresentada.

${ }^{1}$ Área florestal em Baden-Württemberg: 1.256.000ha (37,1\% da área total do estado), área de floresta privada e municipal: $958.328 \mathrm{ha}$ (76,3\% da área florestal). 
Em primeiro lugar, a definição dos objetivos a serem alcançados não está suficientemente formulada. A sua redação é muito genérica e, por isso, não é possível controlar adequadamente o seu efeito. O objetivo "melhoramento da situação econômica das empresas florestais", por exemplo, foi descrito sem parâmetros, sendo necessário definir seus objetivos e critérios operacionais com precisão.

Em segundo lugar, os programas de estímulo, muitas vezes, tornam-se sem efeito, como por exemplo, o incentivo à execução de tarefas na floresta que são normalmente realizadas mesmo sem o financiamento. Nesse caso, os incentivos tornam-se puros programas de transfer. O proprietário recebe dinheiro sem mudar seu comportamento, o que se chama 'levar vantagem' ou free-riderproblem.

Em terceiro lugar, os incentivos dependem das decisões orçamentais, ou seja, dependem quase, exclusivamente, da disponibilidade orçamentária.

Em quarto lugar, citam os problemas de informação. Os vários usuários não recebem as mesmas informações. Por exemplo, as empresas florestais municipais recebem mais informações pelo apoio recebido das empresas florestais estaduais em comparação com as empresas florestais privadas ${ }^{2}$.

Em quinto lugar, é a falta o controle do sucesso. Por causa da falta de critérios para controlar o alcance dos objetivos não é possível medir o sucesso dos incentivos.

\section{CONCLUSÃO}

Portanto, na Alemanha, por meio dos incentivos fiscais, os efeitos externos positivos da produção florestal são internalizados. Entretanto, em razão da falta dos critérios exatamente definidos não se pode verificar se os incentivos no ano 1993, numa quantidade de US\$ 76,72 milhões, destinados às empresas florestais privadas e municipais, foram muito baixos, suficientes ou muito altos.

Apesar dos problemas descritos no complexo sistema de incentivos à produção florestal, a sua existência não é questionada nem pelo governo e nem pelos receptores. Entretanto, é consenso que necessita ser aperfeiçoado.

\section{REFERÊNCIAS}

BRANDL, H. \& OESTEN, G. 1996. Monetäre Bewertung positiver und negativer Effekte der Forstwirtschaft Erfahrungen und Perspektiven. Pp 441-471. In: G. Linckh, H. Sprich, H. Flaig, H. Mohr, (eds.), Nachhaltige Land- und Forstwirtschaft. Expertisen, Berlin, Heidelberg. 471 p.

ELSASSER, P. 1974. Der Erholungswert des Waldes: monetäre Bewertung der Erholungsleistung ausgewählter Wälder. Sauerländer, Deutschland, Frankfurt. 218p.

KAPP, K.W. 1979. Soziale Kosten der Marktwirtschaft. Fischer, Frankfurt. 320 p.

NIESSLEIN, E. 1979. Waldbewertung im nicht-produktionswirtschaftlichen Bereich. Der Forst- und Holzwirt, 3: 25-31.

OESTEN, G. 1994. Zur Wertschätzung der Infrastrukturleistungen des Pfälzerwaldes. Mitteilungen aus der Forstlichen Versuchsanstalt Rheinland-Pfalz, Trippstadt. 265 p.

PETRI, G. 1971. Der land und forstwirtschaftliche Bodenmarkt in Baden-Württemberg. Schriftenreihe der Landesforstverwaltung Baden-Württemberg, Stuttgart, n. 37, 32 p.

SCHÄFER, S. 1989. Die Infrastrukturleistungen des Waldes aus ökonomischer Sicht. Mitteilungen der Forstlichen Versuchs-und Forschungsanstalt Baden-Württemberg, Abt. Betriebswirtschaft, n. 27, 10 p.

SPATHELF, P. 1988. Sozialbilanz des Staatsforstbetriebes von Rheinland-Pfalz. Freiburg A. B. Diplomarbeit, Institut für Forstökonomie, Universität Freiburg. 110 p.

TROMP, H. 1971. Der Wald als Element der Infrastruktur. Schweizer Zeitschrift für Forstwesen, 32(6): 528-541.

Submetido em 07/07/2007

Aceito em 24/08/2007

\footnotetext{
${ }^{2} \mathrm{Na}$ Alemanha há três grupos dos proprietários florestais: floresta estadual, floresta municipal, floresta privada. A proporção dos respectivos grupos depende sobre tudo da história de cada País.
} 